\title{
Point cloud vs drawing on archaeological site
}

\author{
Emmanuel ALBY \\ INSA de Strasbourg \\ Icube laboratory, Photogrammetry and Geomatics, Graduate School of Science and Technology (INSA), 24 Boulevard de la \\ Victoire, 67084 STRASBOURG, France \\ emmanuel.alby (at)insa-strasbourg.fr
}

Session C-3 Modeling methods for architecture and archaeology

KEY WORDS: Archaeology, Drawing, Cultural Heritage, Recording, Terrestrial, Photogrammetry, Laser Scanning,

\begin{abstract}
:
Archaeology is a discipline closely related to the representation of objects that are at the center of its concerns. At different times of the archaeological method, representation approach takes different forms. It takes place on the archaeological excavation, during the exploration, or in a second time in the warehouse, object after object. It occurs also in different drawing scales. The use of topographical positioning techniques has found its place for decades in the stratigraphic process. Plans and sections are thus readjusted to each other, on the excavation site. These techniques are available to the archaeologist since a long time. The most of the time, a qualified member of the team performs himself these simple topographical operations. The two issues raised in this article are: three-dimensional acquisition techniques can they, first find their place in the same way on the excavation site, and is it conceivable that it could serve to support the representation? The drawing during the excavations is a very time-consuming phase; has it still its place on site? Currently, the drawing is part of the archaeological stratigraphy method. It helps documenting the different layers, which are gradually destroyed during the exploration. Without systematic documentation, any scientific reasoning cannot be done retrospectively and the conclusions would not be any evidence. Is it possible to imagine another way to document these phases without loss compared to the drawing? Laser scanning and photogrammetry are approved as acquisition techniques. What can they bring more to what is already done for archaeologists? Archaeological practice can be seen as divided into two parts: preventive archeology and classical archeology. The first has largely adopted the techniques that provide point clouds to save valuable time on site. Everything that is not destroyed by the archaeological approach will be destroyed by the building construction that triggered the excavations. The practice of classical archeology by academics is less governed by the on-site timesaving. The excavation is also the place of the transmission of knowledge and the time spent is beneficial to students. But experimenting with the production of point clouds by archaeologists of emergency can influence the practices of archeology as a whole. An experiment is ongoing on the Saint-Hilarion Monastery site in the Gaza Strip. Each layer of a stratigraphic excavation area was documented by photogrammetry. This project was the means to transfer knowledge related to photogrammetry to allow the archaeologist to document the stratigraphic layers one after the other. Indeed it is essential that this documentation is systematic and not dependent on the availability of specialist in photogrammetry. The risks related to possible wrong practices of photogrammetry by archaeologist are identified, and solutions are proposed. Monitoring means of photogrammetric missions must be established to allow complete and usable documentation. The methods implemented are already applied on other archaeological sites and help save precious time
\end{abstract} on site.

\section{INTRODUCTION}

The practices of the representation of archeology have evolved is recent years. Our view is based on the observation of this development. The three-dimensional data is a source of progress on "vector" data such as the drawing made during the archaeological excavation. It is essential to ask the question of the contribution of the point cloud over the drawing. The answer to this question is obvious for all professionals concerned. It is not interesting because everyone responds differently. Unavoidable, necessary or useless! The speeches of 3D data providers, their users or their critics are of course all based on good reasons that we seek to develop here to better define the representation of the archaeological excavation. We will identify at first what we are interested in the archaeological drawing and then we will discuss the added value that the acquisition techniques can achieve to represent the excavation site and discuss the relevance of their use by professionals and finally we present an application project.

\section{METHOD OF ARCHEOLOGY REPRESENTATION BY DRAWING}

To consider the problematic of representation in archeology, we must take an interest in drawing as exclusive documentation support. The role of archeology drawing is detailed in this section.

\subsection{Thinking and research tool}

Archaeology is a scientific discipline based on the rational discovery of artifacts. Methods have therefore been implemented to reconstruct the history of the occupation of the sites. Its methods are based on stratigraphy (Wheeler, 1954). The establishment of a stratigraphy allows the dating of objects, sorted by date descending compared to their altitude. To complete this step during an excavation, it must continually destroy the recent layers to go investigate the oldest layers hoping to understand the relations of cause / consequence between them. A layer is destroyed to better understand it and explain it. There is therefore a strong need to keep as much information as possible about the stratigraphic layers before their disappearance. The drawing plays that role ever since. It 
allows information to be displayed to let a subsequent reclaiming the context of discovery of the objects in each layer. We associate representations in plan and sections at different scales depending on the objects in place and their interrelationships. The drawing is accessible to all and is very effective. It is therefore an essential tool on site. It is also a synthesis tool. Depending on the type of information you want to include, the lines will be different. If this is the relief that have importance or path or both, the resulting drawing will take varying forms. (Bavay, 2012)

\subsection{Communication, restitution and cultural mediation support}

We have previously seen that the drawing takes a large part in archaeological reasoning on the excavation site. Its mission for archeology is not limited to this. It will extend the perception of the archaeologist on the stratigraphic layer to the postexcavation period. Once all the stratigraphic layers defined are extracted, it is necessary to organize the extracted elements and to build the history of the site. Each of the findings should then be a support to thematic or general communications, based on graphical representations, extracted from existing documents or created for the occasion. Objects after objects, the systematic documentation is done from all objects that were extracted from the site and that are representative of periods traversed by the site. (Harris, 1979)

\subsection{Method of archaeological drawing}

The drawing, as a faithful representation of an object, must be objective and allow figuring exactly all visible characteristics. Indeed the main purpose is that it is readable and therefore follows universal codes of representation. Its envelope that discerns in relief characterizes the subject that interests the draftsman. If the object is similar to a bas-relief, a single view parallel to the plane including the forms stands out enough. Otherwise, multiple views will be needed to complete description of its shape. The draftsman therefore follows the drawing rules by isometric orthographic projection. He will choose a reference plane and he will setup axes to define views. He will use selected measures and considered as structural to the drawing. (Otte, 2003)

\subsection{Ambiguity of the drawing with regard to the draftsman}

In the preceding paragraph we expose the fact that the drawing is derived from choices made by the draftsman. The choice and use of a limited number of measures are a source of differences between two draftsmen, or even by the same one at different times. A single object can be represented differently depending on the choices and structural inaccuracies of archeological drawing. It is dependent on the draftsman who is in his way (Bavay, 2012), despite the many methods in place (Otte, 2003). Repeatability is also a way to test the objectivity of such a method. The choices of the draftsman go beyond the application of drawing methods. The drawing is the result of a reading an artifact in the first representation phase. Part of features is achieved following an own viewpoint to the draftsman. The specific interpretation affects the final shape of the drawing. It is easy to say that if the drawing is the result of choices and interpreted elements, some details present on the site do not see themselves represented as they can point to a different reality. The draftsman is a source of interpretation; the drawing may not be completely objective and therefore faithful to reality. This is something that can be a source of development in seen to improve the method of representation in archeology.

\section{3D ACQUISITION IN ARCHAEOLOGY}

In this part we want to deal with the use of 3D technology acquisition during archaeological excavations. The point cloud provided on-site brings with its production speed invaluable benefits. Depending on the time available on the field, the views of archaeologists on these techniques differ. Is financial pressure the only lock on the expansion of the use of the $3 \mathrm{D}$ acquisition?

\subsection{Point clouds acquisition techniques}

The type of three-dimensional data is the point cloud. It allows describing in discontinuous and precise way many objects. It contains a basic point description, coordinates, as well as information relating to their color and the acquisition conditions. Both three-dimensional acquisition techniques with on-site applications in archeology are photogrammetry and laser scanning. The resulting data are mainly as a point cloud. They each have their characteristics that guide their use. It is important to note that although than accessible to anyone with three-dimensional data requirements, these two techniques require the knowledge of some principles related to the measure field to avoid producing false and unusable data. Laser scanning provides a point cloud quite easily when compared to the photogrammetry. If properly used, it will provide access to the whole scene virtually and precise to enable detailed analyzes retrospectively. The establishment of the stations must be made in advance. It is not essential that the site be properly illuminated to produce a point cloud. Photogrammetry is positioned in an almost obvious extension of the uses of the archaeologist. In fact the camera is already on site. Used systematically, it is without great effort, the way to get good documentation and a complete representation tool. There is no special set-up to do, except to allow scaling of the resulting model. Technologies related to the fields of $3 \mathrm{D}$ acquisition follow an exponential curve progression. There is no doubt that future developments will increase the number of arguments in favor of the widespread use of three-dimensional acquisition techniques on archaeological sites. Already in 2003, we proposed methods of use of photogrammetry in stages of architectural projects [ALBY CIPA 2003]. The interest lay in proposing the virtualization of existing buildings available during renovation projects. The multi-image photogrammetry took its rise but remained manual. The question of the survey for archeology on the basis of point clouds from laser scanning occurred in [FUCHS 2004]. The potential resided in the capabilities to model in its entirety buildings through the acquisition remotely compared to conventional tools mentioned in paragraph 2.

\subsection{Representation based on point cloud.}

Point clouds, if properly produced, suggest completeness of geometric three-dimensional information from an object. This is an effective type of data when used to describe the surfaces of a $3 \mathrm{D}$ object. When you want to manipulate data and expect to appear accessible way of information, it becomes relevant to produce two-dimensional representations from the cloud. As can be seen with (Landes, 2014), automation of the realization of section from the point cloud is quite possible. Automating the semantic decomposition of entities from the point cloud also allows a preview of interesting way (Macher 2014). The 3D acquisition devices provide a dimensional analogy in the production of point cloud. The point cloud, in shape, is close to the discretization operated during the measurement, but if you want to correctly describe the object, you should give continuity to the information. Surface mesh tends towards the improvement 
of the ratio between real object and virtual surface (Remondino, 2003). Interpolations made to obtain the mesh must be controlled to maintain fidelity of the process. Point clouds and meshes hardly transmit the relief of information if they are not colorized. Each point of point cloud can be associated with a color; lots of scanners are designed for that. The interpretation and use of point clouds are made easier with this feature. The use of colors for the mesh must be made from projecting images repositioned relative to the point cloud. Indeed, the color interpolation points to adjacent faces is not realistic. The corresponding pictures are recovered from scanner or photogrammetric project according to the choice of acquisition. Processing chains are available in photogrammetry software such as PhotoModeler or PhotoScan. Radiometry must be as constant as possible from one image to another. A constraint arises from this remark; during the photogrammetric acquisition on site, the control of lighting management should be permanent. When calculating the texture maps, included in PhotoScan, options are managing transitions between different shots are proposed and give good results.

\subsection{Preventive archaeology and $3 D$ acquisition}

Preventive archeology is related to the notion of urgency. It is characterized as a way to preserve and study archaeological artifacts before their destruction by development works. Without the practice of documentation, everything that is buried under the site of a future realization will disappear. The intervention time is limited. The more you have the time to go deeper into the investigation, the less the project will destroy potential discoveries. Each step must take place as quick as possible. The representation of the stratigraphic layers and objects discovered is an issue in optimizing regarding the time spent.

\subsection{Preventive and classical archeology}

Time is much less of a limiting factor for the practice of archeology in the academic context. Although the sites are deteriorating especially if excavations are delayed (Elter 2008), if they are not directly threatened by a building project, time spent on site is not considered as a factor that promotes the use of 3D acquisition techniques. Archeology and history knowledge increase with the number of discovered sites. Using $3 \mathrm{D}$ acquisition techniques is a way to save time on site, thus minimizing risk taking in unsecured territories but also money saving.

\subsection{Excavation accelerated}

The intervention periods during the excavation can be divided into two distinct types. The excavation stage of stratigraphic layer can be identified to access the previous and oldest one. It is this step that induces the concept of discovery; growth is adapted to the type of substrate (sand, embankments etc.) and the supposed depth thanks to the surveys already made. This phase requires a large number of workers, as well as to remove the layer to disengage the material, sort the artifacts and anything that allows identifications. The other phase that concerns us for this article is the documentation phase, where only a few people are helpful and others are waiting nearby. The more this phase takes time, the more important the costs are. This is the documentation phase we can optimize using 3D acquisition techniques.

\subsection{Future of Unified archaeology?}

Time constraints on the archaeological site tend to be the same for every archaeologist, whether commissioned as part of an emergency excavation or acting on his favorite field. If archeology practices have different opportunities to look at the three-dimensional acquisition, adopting it in a more or less long term is possible.

\section{INFLUENCE OF 3D ACQUISITION ON ARCHAEOLOGICAL EXCAVATION}

Each use of the 3D acquisition in archeology has its peculiarities. The application that will illustrate our thesis in this article is a Christian site at Middle East.

\subsection{Monastery of St. Hilation at Tel um el amr}

The project is presented in detail in (Alby, 2013). We will return to the main features.

The monastery of St. Hilarion was discovered in the Gaza Strip in 1997. The monastery ruins are located $10 \mathrm{~km}$ south of Gaza City. The remains extend over 1.5 hectares and are located on a dune overlooking a palm grove and the sea, located about 300 $\mathrm{m}$. The excavated remains are those of a Byzantine monastery and a bathhouse, dating from the Umayyad period. In 2003, an inscription refers to the place as dedicated to the worship of Saint-Hilarion father of monasticism in the Middle East who lived in the fourth century, and whose texts mention the location of the foundation at Tell Umm El'Amr. Since 2001, the mission of French-Palestinian archaeological cooperation of Gaza, headed by EBAF leads the complete study with the objective remains the restoration and tourism development (Elter 2008). The diversity of the discovered elements of different sizes and materials, requested the adaptation of basic building survey protocols and the use of such methods to circumvent the barriers of site configuration.

The point on which we want to emphasize is the importance of the demonstration of efficacy in the field. For a surveyor, it is obvious that $3 \mathrm{D}$ acquisition techniques are essential in an archaeological context. To the archaeologist who is accountable of the progress of its work, it is significant to observe the implementation of the technique chosen on its own field of intervention. It is thus possible to understand the best methods applied on the remains it is appropriate and he knows how to handle their documentation, representation and valuation.

\subsection{Delegation of the documentation of the excavation}

The feedback on experience with the Archaeologist is mainly related to the fact that he accepted the experience, interested in the timesaving, the potential of proposed cultural mediation. The risk in the delegation photogrammetric shots lies in undetected errors on the field. If you compare the photogrammetrist the archaeologist and that assumes that the skills were transmitted and validated. The Professional of 3D acquisition can more easily check his data with tools on the field. Free photomodeling solutions allow testing its data set even if the precision of these "photogrammetric" tools remains controversial.

\subsection{Autonomy of the archaeologist with respect to its representations.}

The autonomy of the archaeologist in the way to conduct his own shots allows the integration time to acquire photographs in a ritual and daily field visit. The action of drawing is also a moment of inspection of the object; the daily acquisition phase takes the same part as the drawing. One advantage to improve the photogrammetric acquisition comes in multi-scale dimension it offers. The surveyor cannot be on the site as often as the purpose of this article encourages; the independence of the 
archaeologist or any permanent of the excavation site is the crucial regarding to the $3 \mathrm{D}$ acquisition. The effort to develop this tool is not negligible in the early days but the experiment shows that the time saved when integrated product is worth the investment.

\subsection{Complete documentation over time}

Stratigraphic layers were systematically recorded by photogrammetry. The survey is based on a large overlap images and provides a high density of point clouds.

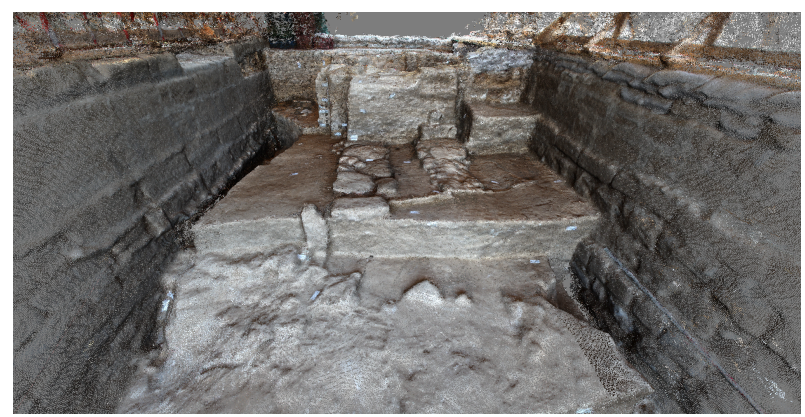

Figure 1: Point cloud of excavation

As it can be noticed in Figure 1, the colored point cloud already allows obtaining a very effective understanding support. As we have seen in 3.2 , the textured mesh is the most accurate way to establish the analogy field / virtual model. Figure 2 shows the same view as the previous but with the textured mesh model. Using Photoscan provides a result where radiometry is very well managed and avoids misinterpretations due to changes in light.

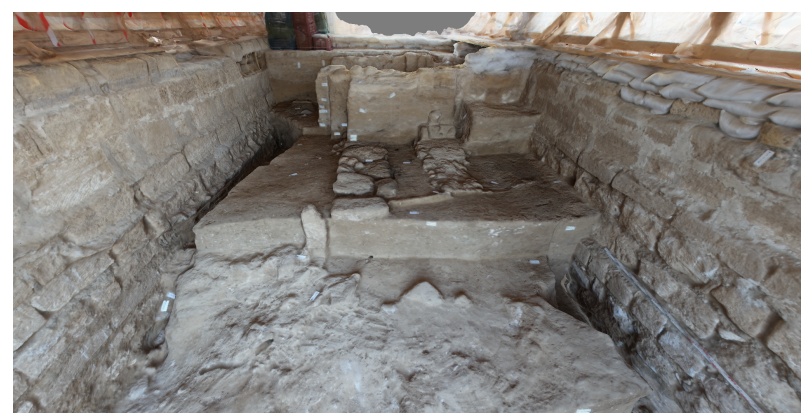

Figure 2: textured mesh processed from point cloud

Once the point clouds produced from different stratigraphic layers registered; the available data suggest a good perception of every stratigraphy simultaneously. The product dataset is a very powerful archaeological analysis tool.

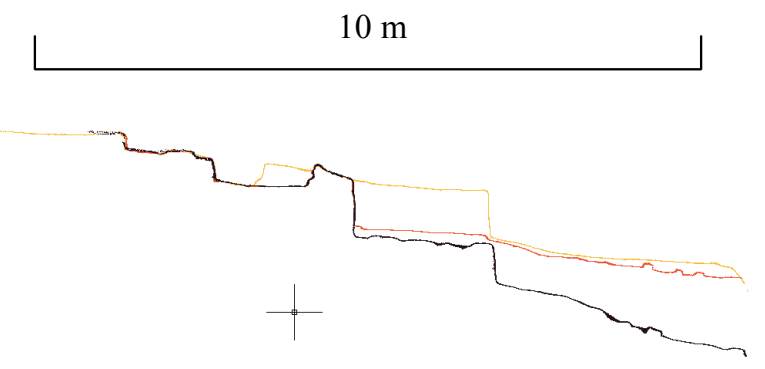

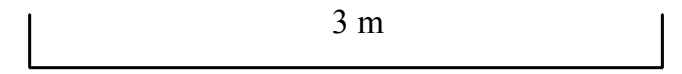

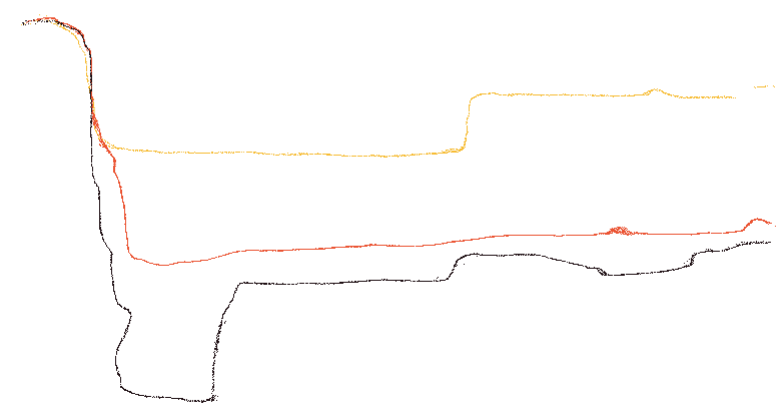

Figure 4: cross section through three stratigraphic layers

Figures 3 and 4 demonstrate the interest of the systematic survey of stratigraphic layers. Transverse and longitudinal sections in three different stratigraphic layers are made very easily from the time when all the point clouds are properly recalibrated them. We can further analyze the stratigraphic thickness of each layer and thus, also their composition, understand their constitution. Product quality of photogrammetric chain operates in the production of orthophotos. Archaeologists already very often use the picture, as an aid to representation; 3D scanning techniques have such potential to produce this type of data. Figures 5 and 6 are ortho-images produced directly from the textured 3D model. The example in this article concerns the complete excavation (dimensions $11 \mathrm{~m} \times 4.5 \mathrm{~m}$ ), but it is easy to transpose the arguments to other scales. Unlike laser scanning, photogrammetry is usable at multiple scales without changing acquisition device. Although photographs require more photographic skill when the subject is small (of the order of a meter), the distance is shorter; the benefits of photogrammetry are similar to those shown in our example.

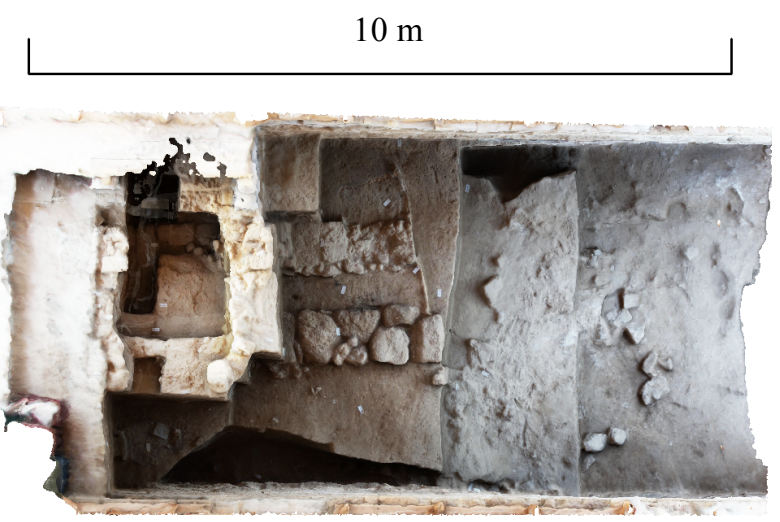

Figure 5: Ortho-photo from textured mesh, Top view

Figure 3: Longitudinal section through three stratigraphic layers 


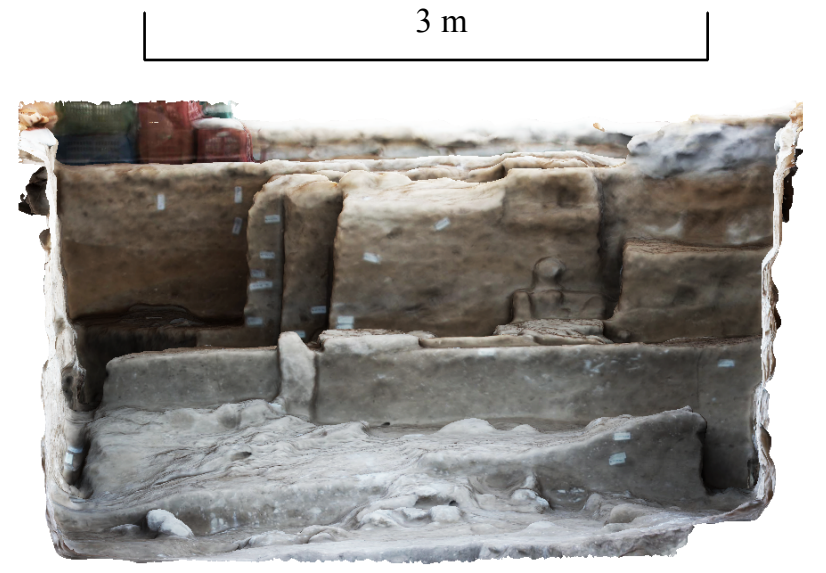

Figure 6: Ortho-projection from textured mesh, Front view

\section{CONCLUSION}

The archeology representation is inseparable from its practices. The documentation is done progressively to avoid losing information by destroying a stratigraphic layer. Currently, the design takes a large part in the action of figuration; it takes significant time in relation to the duration of the excavation. We have seen that the acquisition techniques have evolved and are operational for representation at the time of excavation and postexcavation. Their use allows accelerating the documentation phase on field, which is an obvious progress. It remains locks on their use by archaeologists anyway. It is therefore essential to accompany the site manager to a rational use of these tools that are accessible to those who can benefit from it. We have shown that far from replacing the drawing, documentation by point cloud is a way to organize the time of archaeological excavation. The point cloud, if the method of acquisition is controlled is an excellent support for the archaeologist, the representation as we have seen but for restitution and cultural mediation. The adoption of $3 \mathrm{D}$ acquisition technology in the early stages and their integration into the methods is a way to save time throughout the archaeological approach.

\section{ACKNOWLEDGEMENTS}

René ELTER Director of French-Palestinian archaeological mission in Tell Umm el-Amr, Gaza strip

Lorraine university, EA 1132 Hiscant-Ma.

French Biblical and Archaeological School (EBAF), 6 Nablus Road P.O.B. 1905391190 Jerusalem JERUSALEM.

General Consulate of France in Jerusalem and the Al-Maqdisi program to strengthen scientific and cultural ties between French researchers and Palestinian.

\section{BIBLIOGRAPHY :}

Alby, E., Elter, R., Ripoche, C., Quere, N., (2013). Close Range Photogrammetry Applied to the Documentation of AN Archaeological Site in Gaza Strip, Palestine. ISPRSInternational Archives of the Photogrammetry, Remote Sensing and Spatial Information Sciences, 1(2), 19-24.

Wheeler, M. (1955). Archaeology from the Earth.

Harris E (1989) Principles of archaeological stratigraphy, 2nd edn. Academic Press, London
Alby, E., Grussenmeyer, P., Perrin, J.-P.. Integration of close range photogrammetric surveys in the design process of architectural projects. In: Proceedings of CIPA XIX international symposium, Antalya, Turkey; 46-51, 2003.

Bavay, L.. Dessiner pour... comprendre le passé. In Insoupçonnables beautés de la recherche. Le dessin dans les collections de l'ULB, Bruxelles, Réseau des Musées de l'ULB, M. Depraetere, N. Gesché-Koning et N. Nyst,

Elter, R., \& Hassoune, A. (2008). Le complexe du bain du monastère de saint Hilarion à Umm el-'Amr, première synthèse architecturale. Syria, 129-144.

Fuchs, A., Alby, E., Begriche, R., Grussenmeyer, P., Perrin, J.P.. Confrontation du Relevé Laser 3D Aux Techniques de Relevé Conventionnelles et Développement D'outils Numériques Pour la Restitution Architecturale. Revue de la Société Française de Photogrammétrie et de Télédétection $\mathrm{n}^{\circ}$ 173/174 (2004-1/2), 2004. p. 36-47.

Otte M.. Lire le Passé. Méthodes de fouilles archéologiques, 2003, Univ. Libre de Liège, 152 p.

Landes, T., Bidino, S., \& Guild, R. (2014). Semi-Automatic extraction of sectional view from point clouds. The Case of Ottmarsheim's abbey-church. Int. Archives of the Photogrammetry, Remote Sensing and Spatial Information Sciences, Italy.

Macher, H., Landes, T., Grussenmeyer, P., Alby, E. (2014). Semi-automatic Segmentation and Modelling from Point Clouds towards Historical Building Information Modelling. In Digital Heritage. Progress in Cultural Heritage: Documentation, Preservation, and Protection (pp. 111-120). Springer International Publishing.

Remondino, F., From point cloud to surface: the modeling and vizualisation problem. In: Proceedings of ISPRS International workshop on vizualisation and animation of reality-based 3D models, Tarasp-Vulpera, Switzerland, 2003.

Remondino, F., \& El-Hakim, S. (2006). Image-based 3D Modelling: A Review. The Photogrammetric Record, 21(115), 269-291.

Suméra, F.. " Archéologie du bâti, scanner 3D et orthophotographie, Vraie réponse ou fausse solution », in V. Mathieu et $\mathrm{R}$. Thernot, L'imagerie virtuelle en archéologie : présentation d'outils et retours d'expériences, UMR 5140 symposium. february 2010 